\title{
Efficiency of caries risk assessment in young adults using Cariogram
}

\author{
Esra Uzer Celik \\ Necmi Gokay² \\ Mustafa Ates $^{3}$
}

\begin{abstract}
Objective: The aims of this study were to: (1) evaluate the caries risk in young adults using Cariogram and (2) compare the efficiency of Cariogram with the regression risk models created using the same variables in Cariogram by examining the actual caries progression over a 2-year period.

Methods: This study included 100 subjects that were either twenty or twenty-one years-old. Data on general health, diet, oral hygiene and use of fluoride were obtained. Saliva analyses were performed, including mutans streptococci and lactobacilli counts, secretion rate and buffer capacity. DMFT and DMFS values were calculated by clinical examinations and radiographs. The participants were divided into 5 groups according to their Cariogram caries risk scores at baseline. Re-examination for caries was done after 2-years. The data were analyzed using Kruskall Wallis, Mann Whitney$\mathrm{U}$, and logistic regression analyses.

Results: Diet frequency, plaque amount and secretion rate were significantly associated with caries increment $(\mathrm{P}<.05)$. Cariogram and the regression risk models explained the caries formation at a higher rate than single-variables. However, the regression risk model developed by diet frequency, plaque amount and secretion rate explained the caries formation similar to Cariogram, while the other regression model developed by all variables used in Cariogram explained the caries formation at a higher rate than this computer program.

Conclusions: Cariogram is effective and can be used for caries risk assessment instead of single variables; however, it is possible to develop simplier models with regression analyses to determine caries risk. (Eur J Dent 2012;6:270-279)
\end{abstract}

Key words: Caries risk; Cariogram; caries risk model; risk factor

1 Department of Restorative Dentistry, Faculty of Dentistry, Izmir Katip Celebi University, Izmir, TURKIYE 2 Department of Restorative Dentistry, School of Dentistry, Ege University, Izmir, TURKIYE

${ }^{3}$ Department of Basic and Industrial Microbiology, Faculty of Science, Ege University, Izmir, TURKIYE

- Corresponding author: Dr. Esra Uzer Celik Department of Restorative Dentistry, Faculty of Dentistry, Izmir Katip Celebi University, Izmir, TURKIYE Tel: +90 2323254040 int. 2210 Fax: + 902323293999 Email: esrauzerdyahoo.com

\section{INTRODUCTION}

A key factor for planning any preventive program is to accurately assess a person's risk of developing a disease. Dental caries is a multifactorial disease and is affected by several factors, such as the patient's general health and diet, the amount and type of bacteria present in the oral cavity, salivary factors and exposure to fluoride. ${ }^{1-3}$ Thus, caries risk assessment approaches should 
take into account risk implications from various factors that influence carious activity.

To date, various cross-sectional and longitudinal studies regarding caries risk assessment have been reported. ${ }^{4-8}$ In cross-sectional studies, the caries related factors identified, measured and corelated the history of caries or the actual caries status of patient. $4,7,8$ Longitudinal studies assessed the relation of factors with the progression of caries over a period of time, usually 1-3 years. ${ }^{5,6}$ In those studies, the accuracy of many different caries activity tests assessing saliva buffer capacity, flow rate, saliva or plaque mutans streptoccocci and lactobacillus amounts were evaluated. However, no single variable was proven to be successful in predicting caries development as that single variable would only evaluate one factor that could influence caries formation. 6,7 The multifactorial etiology of dental caries points to the necessity of developing new caries risk assessment models that would include the different factors or parameters which influence new carious lesions.

Two different approaches were described for caries risk assessment models: the risk model and the prediction model. ${ }^{9}$ The risk model determines causative caries factors called risk factors but does not predict the caries outcome. The prediction model is the estimation of the risk of caries progression in the future. Since the 1980s, several multivariable caries risk strategies have been developed using the concepts mentioned above. Risk models including multiple variables result in better predictions because the disease process is multifactorial. ${ }^{10,11}$ The most commonly used statistical methods for caries risk assessment are multivariate regression analyses..$^{12}$

The most recent caries risk model is a computer program, Cariogram, which assesses an individual's caries risk profile by illustrating it graphically. The Cariogram algorithm was built on "full facts and circumstances". It weighs each etiological factor at a relevant ratio. Moreover, this program elucidates the percentage of risk owing to each etiological factor and the total risk that is calculated by weighing together all of the etiological risks. This software also suggests preventive measures to avoid the formation of new caries. ${ }^{13,14}$

This computer program has been evaluated in previous studies for its capacity to predict caries. ${ }^{13-15}$ These studies showed that it predicted car- ies progression more accurately than any singlefactor model. However, there is limited number of studies that have compared the efficacy of Cariogram with the other caries risk models. ${ }^{16}$

The aims of this current study were to: (1) evaluate the caries risk in young adults (20-21 years old participants) using the Cariogram program and (2) compare the efficiency of the Cariogram program with the regression risk models created using the same variables in Cariogram by examining the actual caries progression over a 2-year period.

\section{MATERIALS AND METHODS}

A hundred volunteers (56 male and 44 female), between the ages of 20-21, who referred to our clinic between 1 January 2004 - 1 January 2005 for their dental treatments and accepted to take part in this study were included.

The human ethical research committee of the Ege University approved the study protocol and written consent was obtained from each patient at the beginning of the study. The exclusion criteria were as follows:

\section{Exclusion criteria:}

1. Having chronic or acute upper respiratory diseases because respiratory diseases may affect the oral flora and the antibacterial compounds of saliva, ${ }^{17-18}$

2. Use of chlorhexidine gluconate solutions over the last three months,

3. Fixed orthodontic appliances,

4. Taking antibiotics over the last month.

Preparation of a questionnaire and an interview with the participants

The questionnaire and interview focused on questions about general health, diet, number of meals and snacks per day, oral hygiene and use of fluoride. An individual interview was performed with the participants in a separate room and the answers of the questionnaire were discussed with the participants during the interview.

\section{Intraoral and radiographical examination}

All examinations were performed by the same examiner. The oral hygiene and plaque amount were estimated using a mirror and periodontal probe in accordance with the Sillness and Löe plaque index. The participants were classified into one of four groups: extremely good, good, bad, and 
very bad oral hygiene according to the Cariogram Manual. ${ }^{19}$

The level of caries was scored by visual evaluation and bitewing radiographs in the dental clinic. After drying the teeth with air, each tooth surface was examined and they were recorded as decayed, missing or filled tooth/surface (DMFT/DMFS). Caries was defined in accordance with the World Health Organization (WHO) criteria. ${ }^{20}$ A tooth was recorded as decayed when there was visible evidence of cavitation, including dentin and an approximately tranclucency into the dentin on the bitewing radiographs. In order to perform the radiographs properly, Hawe X-Ray Film Holder System (Hawe Neos Dental SA, Bioggio, Switzerland) was used.

\section{Saliva sampling}

Stimulated whole saliva was collected to measure saliva secretion rate, buffer capacity, and counts of lactobacilli and mutans streptococci. The participants were asked to chew on a piece of sugar, xylitol or sorbitol free gum for $1 \mathrm{~min}$ and then expectorate the saliva. The chewing process was continued for $5 \mathrm{~min}$ and stimulated whole saliva was collected in sterile containers. The amount of saliva was then measured by a sterile syringe. The saliva samples were transported immediately to the laboratory and processed within $2 \mathrm{~h}$ of collection.

Dentobuff Strip (Orion Diagnostica, Espoo, Finland), a chair-side method, was used to measure the buffering capacity of saliva handled according to the instructions of the manufacturer.

\section{Microbial evaluation}

The saliva samples were vortexed for $30 \mathrm{~s}$ and serially diluted in sterile saline solution (1/101/10.000). Mitis Salivarius Bacitrasin (MSB) Agar (Difco, Le Pont de Claix, France) and De Man, Rogosa and Sharpe (MRS) agar (Difco) were inoculated with diluted saliva to evaluate the presence of mutans streptococci and lactobacilli, respectively. The plates were incubated in an atmosphere of $95 \% \mathrm{~N}_{2}$ and $5 \% \mathrm{CO}_{2}$ at $37{ }^{\circ} \mathrm{C}$ for $48-72 \mathrm{~h}$ and the colony forming units (CFU) were identified by morphology and counted in a stereomicroscope.

Creating a risk profile using the Cariogram

The results of the questionnaire, clinical evalu- ation, and saliva tests were entered into the Cariogram computer program to determine each patient's caries risk profile (Table 1). ${ }^{13,19}$ Cariogram assessed the risk of future caries activity and expressed the result as "the chance of avoiding caries". The chance varies on a scale from 0 to $100 \%$. A $0 \%$ chance means that lesions will definitely occur, while $100 \%$ chance indicates that there is no risk for future caries.

Re-examination for caries was performed after 2 years by visual evaluation and bitewing radiographs and the caries increment over two years was calculated.

\section{Statistical analysis}

The statistical analysis was processed with the SPSS 13.0 software system (SPSS Inc., Chicago, Illinois, USA). The differences in caries scores across categories of different variables were compared using Kruskall Wallis and Mann Whitney-U tests. The probability level for statistical significance was at $a=.05$.

Cariogram risk categories and variables of all participants were analyzed for relationships with future caries using a logistic regression analysis with likelihood ratio tests. Regression risk models were developed using variables used in Cariogram.

Logistic regression analyses were carried out using DMFS increment (caries/no caries) over 2 years as the response variable. The variables entered were: caries experience, diet content lexpressed as lactobacilli counts), diet frequency, amount of plaque, mutans streptococci in saliva, use of fluoride, saliva secretion rate, buffer capacity, and the Cariogram. Each independent variable was scored as described according to the study of Hansel Petersson et al. ${ }^{13}$

\section{RESULTS}

All volunteers were evaluated after 2 years (100\% recall rate). Most of the volunteers (70\%) were undergraduate students at the university; the others $(30 \%)$ were working.

The distribution of participants according to the DMFT score at baseline and at the end of follow-up is shown in Table 2. The mean DMFT and DMFS values of participants were respectively $7.36 \pm 4.2$ and $10.61 \pm 7.43$ at baseline, these values increased to $7.78 \pm 4.33$ and $13.25 \pm 9.58$ at the follow-up evalu- 
ation. Thirty-one participants had developed new caries after 2 years.

The participants were divided into 5 groups at baseline according to the chance of avoiding caries. The participants with a $0-20 \%$ chance of avoiding caries were the highest risk group, while the group with the lowest predicted risk for caries had an $81-100 \%$ chance of avoiding caries. The number of participants in each risk group, at baseline and at follow-up is shown in Table 3. There was no increase in DMFT scores of the lowest risk group, while it was $1.23 \pm 0.86$ in the highest risk group. When the groups were compared according to the number of newly developed caries, group 1 and group 2 were significantly different from group 3 , group 4 and group $5(\mathrm{P}<.05)$.

The mean DMFT and DMFS increments and the mean number of newly developed carious lesions for each of the caries-related variables are presented in Table 4. The DMFT and DMFS increments may be changed by the other factors than caries such as fillings, extraction and the side of

Table 1. Caries related factors used at baseline and the Cariogram scores for these factors.

\begin{tabular}{|c|c|c|}
\hline Factors & Information and data collection & Cariogram scores \\
\hline \multirow{4}{*}{ Caries experience } & \multirow{4}{*}{$\begin{array}{l}\text { Past caries experience at baseline, including } \\
\text { cavities, fillings, and missing teeth due to caries. } \\
\text { Data from dental records and bitewing radiographs. }\end{array}$} & 0 : Caries free, no fillings \\
\hline & & 1: Better than normal \\
\hline & & 2: Normal for that age group \\
\hline & & 3: Worse than normal \\
\hline \multirow{3}{*}{ Related diseases } & \multirow{3}{*}{$\begin{array}{l}\text { General disease or conditions associated with } \\
\text { dental caries. Medical history, medications; data } \\
\text { from interviews and questionnaire results. }\end{array}$} & $0:$ No disease, healty \\
\hline & & $\begin{array}{l}\text { 1: A general disease, which can indirectly influence the } \\
\text { caries process to a mild degree }\end{array}$ \\
\hline & & $\begin{array}{l}\text { 2: A general disease, which can indirectly influence the } \\
\text { caries process to a high degree. }\end{array}$ \\
\hline \multirow{4}{*}{ Diet, contents } & \multirow{4}{*}{$\begin{array}{l}\text { In this study, lactobacillus counts were used as a } \\
\text { measure of cariogenic diet; data from lactobacillus } \\
\text { test count. }\end{array}$} & $0: \leqslant 10^{3} \mathrm{CFU} / \mathrm{ml}$ \\
\hline & & 1: $10^{4} \mathrm{CFU} / \mathrm{ml}$ \\
\hline & & 2: $10^{5} \mathrm{CFU} / \mathrm{ml}$ \\
\hline & & $3: \geqslant 10^{6} \mathrm{CFU} / \mathrm{ml}$ \\
\hline \multirow{4}{*}{ Diet, frequency } & \multirow{4}{*}{$\begin{array}{c}\text { Estimation of number of meals and snacks per day, } \\
\text { mean for 'normal days'; data from interviews and } \\
\text { questionnaire results. }\end{array}$} & $0:$ Maximum 3 for meals per day \\
\hline & & 1: 4-5 meal per days \\
\hline & & 2: 6-7 meals per day \\
\hline & & 3: >7 meals per day \\
\hline \multirow{4}{*}{ Plaque amount } & \multirow{4}{*}{$\begin{array}{l}\text { Data from the clinical examination of oral hygiene } \\
\text { according to Silness-Löe Plaque Index. }\end{array}$} & 0 : Very good oral hygiene, $\mathrm{Pl}<0.4$ \\
\hline & & 1: Good oral hygiene, $\mathrm{PI}=0.4-1$ \\
\hline & & 2: Poor oral hygiene, $\mathrm{Pl}=1.1-2$ \\
\hline & & 3: Very poor oral hygiene, $\mathrm{Pl}>2$ \\
\hline \multirow{4}{*}{ Mutans streptococci } & \multirow{4}{*}{ Estimation of levels of mutans streptococci in saliva } & $0: \leqslant 10^{3} \mathrm{CFU} / \mathrm{ml}$ saliva \\
\hline & & 1: $10^{4} \mathrm{CFU} / \mathrm{ml}$ saliva \\
\hline & & 2: $10^{5} \mathrm{CFU} / \mathrm{ml}$ saliva \\
\hline & & $3: \geqslant 10^{6} \mathrm{CFU} / \mathrm{ml}$ saliva \\
\hline \multirow{4}{*}{ Fluoride program } & \multirow{4}{*}{$\begin{array}{l}\text { Estimation of the extent of fluoride available in the } \\
\text { oral cavity; data from interview or questionnaire } \\
\text { results. }\end{array}$} & 0: Maximum fluoride program \\
\hline & & 1: Fluoride supplements \\
\hline & & 2: Only fluoride toothpaste \\
\hline & & 3: No fluoride \\
\hline \multirow{4}{*}{ Saliva secretion rate } & \multirow{4}{*}{ Estimation of flow rate of stimulated saliva. } & $0:>1.1 \mathrm{ml} / \mathrm{min}$ \\
\hline & & $1:>0.9-1.1 \mathrm{ml} / \mathrm{min}$ \\
\hline & & $2: 0.5-0.9 \mathrm{ml} / \mathrm{min}$ \\
\hline & & $3:<0.5 \mathrm{ml} / \mathrm{min}$ \\
\hline \multirow{3}{*}{ Saliva buffering capacity } & \multirow{3}{*}{$\begin{array}{c}\text { Estimation of capacity of saliva to buffer acids using } \\
\text { the Dentobuff Strip test. }\end{array}$} & $0: \mathrm{pH} \geqslant 6$ \\
\hline & & $1: \mathrm{pH}=4.5-5.5$ \\
\hline & & $2: \mathrm{pH} \leqslant 4$ \\
\hline
\end{tabular}


the caries. Thus, the statistical analysis was performed according to the newly developed carious lesion. When the differences in caries scores across categories of different variables were compared, no significant differences were found among the categories of saliva buffering capacity, mutans streptoccoci counts, diet contents, past caries experience and fluoride program.

There were significant differences among the different categories of diet frequency. The participants who had a maximum of 3 meals per day developed fewer new carious lesions than the other groups $(P<.05)$. In addition, participants who had 4-7 meals per day developed fewer caries than the ones who had more than 7 meals per day $(P<.05)$.

The differences among the different categories of plaque amount were significant $(P<.05)$. The participants with very good and good oral hygiene developed fewer new carious lesions than the ones with poor or very poor oral hygiene $(P<.05)$.

There were significant differences among the different categories of saliva secretion rate $(P<.05)$. The participants with a normal saliva secretion rate developed fewer new carious lesions than the other groups $(\mathrm{P}<.05)$.

When all of the independent variables that are used for the Cariogram program were entered in the regression model; plaque amount, diet fre- quency, and saliva secretion were found to be significantly associated with caries progression. Plaque amount, diet frequency, and saliva secretion explained 24, 28, and 12 percent (Negelkerge $\mathrm{R}$ Square value) of the variance in development of new caries lesions, respectively. According to the regression analyses, the regression model that included the plaque amount, diet frequency, and saliva secretion explained the caries risk at a similar rate $(49 \%)$ to did Cariogram (46\%). The regression model that included all of the independent variables explained the caries risk at a higher rate (65\%) than did Cariogram (46\%).

The odds ratio for the different Cariogram groups, diet content scores, plaque amount scores, and saliva secretion scores are given in Table 5 . The odds ratio is a way of comparing whether the probability of a certain event is the same for two groups. For example, the children in the highest risk group (0-20\% chance of avoiding caries) had a risk 80 times greater than that of the young adults in the lowest-risk group $181-100 \%$ change of avoiding caries).

\section{DISCUSSION}

To date, researchers have been looking for the factors that would enable them to predict who would develop a carious lesion. Most variables that

Table 2. The distribution of participants according to the DMFT scores at baseline and at the end of follow-up.

\begin{tabular}{lcc}
\hline DMFT & Baseline & Follow-up \\
\hline Score 0 (DMFT=0) & $\mathrm{n}$ & $\mathrm{n}$ \\
\hline Score $1(\mathrm{DMFT}<5)$ & 6 & 4 \\
Score 2 (5<DMFT<7) & 21 & 18 \\
Score $3(\mathrm{DMFT}>7)$ & 27 & 25 \\
Total & 46 & 53 \\
\hline
\end{tabular}

Table 3. The number of participants in each risk group according to Cariogram, at baseline and at follow-up.

\begin{tabular}{|c|c|c|c|c|c|}
\hline DMFT/DMFS & $\begin{array}{c}0-20 \% \\
\text { (Group 1) }\end{array}$ & $\begin{array}{l}21-40 \% \\
\text { (Group 2) }\end{array}$ & $\begin{array}{l}41-60 \% \\
\text { (Group 3) }\end{array}$ & $\begin{array}{c}61-80 \% \\
\text { (Group 4) }\end{array}$ & $\begin{array}{l}81-100 \% \\
\text { (Group 5) }\end{array}$ \\
\hline \multicolumn{6}{|l|}{ Number of individuals } \\
\hline At baseline $(\%)$ & 13 & 20 & 33 & 24 & 10 \\
\hline At follow-up (\%) & 15 & 26 & 32 & 20 & 7 \\
\hline Mean DMFT at baseline & $10.87 \pm 5.05$ & $7.15 \pm 3.99$ & $8.43 \pm 3.93$ & $6.39 \pm 3.25$ & $3.86 \pm 2.97$ \\
\hline Mean DMFT at follow-up & $12.1 \pm 5.15$ & $7.8 \pm 3.8$ & $8.82 \pm 3.96$ & $6.47 \pm 3.29$ & $3.86 \pm 2.97$ \\
\hline Mean DMFT increment & $1.23 \pm 0.86$ & $0.65 \pm 0.81$ & $0.39 \pm 1.02$ & $0.08 \pm 0.28$ & 0 \\
\hline Mean DMFS increment & $1.23 \pm 0.86$ & $0.9 \pm 0.97$ & $0.48 \pm 1.06$ & $0.08 \pm 0.28$ & 0 \\
\hline Mean number of new developed carious lesion & $1.23 \pm 0.86^{\mathrm{a}}$ & $0.9 \pm 0.97^{a}$ & $0.48 \pm 1.06^{b}$ & $0.08 \pm 0.28^{b}$ & $0^{\mathrm{b}}$ \\
\hline
\end{tabular}

*Different letters in the same line indicate significant differences between the different categories of Cariogram. 
have been investigated were: host, microflora, diet and past caries history. However, no single variable was found successful in predicting caries development in previous studies. ${ }^{6,7}$

Inconsistent results from the single variable tests directed the investigators to develop mul- tivariable caries risk and prediction models. The risk model is used to predict and delineate risk factors in order to develop the most effective prevention and treatment interventions. This model is preferred when the etiology of a disease is not fully understood. The use of a risk model is also

Table 4. The mean DMFT and DMFS increments and the mean number of new developed carious lesions for each of the caries-related variables.

\begin{tabular}{|c|c|c|c|c|}
\hline Factor & $\begin{array}{c}\text { Mean } \\
\text { DMFT increment }\end{array}$ & $\begin{array}{c}\text { Mean } \\
\text { DMFS increament }\end{array}$ & $\begin{array}{c}\text { Mean number of new } \\
\text { developed caries }\end{array}$ & Number of individuals \\
\hline \multicolumn{5}{|c|}{ Diet content } \\
\hline Score 0 & 0 & 0 & $0^{\text {a }}$ & 4 \\
\hline Score 1 & 0 & 0 & $0^{\mathrm{a}}$ & 20 \\
\hline Score 2 & $0.28 \pm 0.67$ & $0.5 \pm 0.86$ & $0.5 \pm 0.8^{\mathrm{a}}$ & 31 \\
\hline Score 3 & $0.53 \pm 0.98$ & $0.57 \pm 0.98$ & $0.54 \pm 0.98^{a}$ & 45 \\
\hline \multicolumn{5}{|c|}{ Diet frequency } \\
\hline Score 0 & $0.03 \pm 0.12$ & $0.06 \pm 1.11$ & $0.06 \pm 0.11^{\mathrm{a}}$ & 23 \\
\hline Score 1 & $0.47 \pm 0.73$ & $0.56 \pm 0.71$ & $0.55 \pm 0.71^{b}$ & 40 \\
\hline Score 2 & $0.45 \pm 0.83$ & $0.72 \pm 0.75$ & $0.69 \pm 0.72^{b}$ & 17 \\
\hline Score 3 & $1.23 \pm 1.41$ & $1.23 \pm 1.41$ & $1.23 \pm 1.41^{\mathrm{c}}$ & 20 \\
\hline \multicolumn{5}{|c|}{ Plaque amount } \\
\hline Score 0 & $0.05 \pm 0.23$ & $0.05 \pm 0.23$ & $0.05 \pm 0.23^{a}$ & 19 \\
\hline Score 1 & $0.25 \pm 0.51$ & $0.25 \pm 0.51$ & $0.23 \pm 0.49^{a}$ & 30 \\
\hline Score 2 & $0.64 \pm 1.11$ & $0.79 \pm 1.13$ & $0.75 \pm 1.14^{b}$ & 33 \\
\hline Score 3 & $1.28 \pm 1.11$ & $1.42 \pm 1.13$ & $1.42 \pm 1.13^{\mathrm{b}}$ & 18 \\
\hline \multicolumn{5}{|c|}{ Mutans streptococci } \\
\hline Score 0 & 0 & 0 & $0^{\mathrm{a}}$ & 6 \\
\hline Score 1 & $0.45 \pm 0.87$ & $0.39 \pm 0.93$ & $0.39 \pm 0.93^{a}$ & 32 \\
\hline Score 2 & $0.54 \pm 0.90$ & $0.62 \pm 0.92$ & $0.60 \pm 0.90^{a}$ & 37 \\
\hline Score 3 & $0.8 \pm 1.1$ & $1 \pm 1.00$ & $0.91 \pm 1.03^{\mathrm{a}}$ & 25 \\
\hline \multicolumn{5}{|c|}{ Fluoride program } \\
\hline Score 0 & 0 & 0 & $0^{a}$ & 4 \\
\hline Score 1 & $0.37 \pm 1.06$ & $0.5 \pm 1.06$ & $0.5 \pm 1.06^{a}$ & 8 \\
\hline Score 2 & $0.4 \pm 0.75$ & $0.54 \pm 0.83$ & $0.53 \pm 0.83^{\mathrm{a}}$ & 88 \\
\hline Score 3 & - & - & - & 0 \\
\hline \multicolumn{5}{|c|}{ Saliva secretion rate } \\
\hline Score 0 & $0.25 \pm 0.75$ & $0.27 \pm 0.78$ & $0.25 \pm 0.75^{a}$ & 83 \\
\hline Score 1 & $1.5 \pm 1.82$ & $1.8 \pm 2.01$ & $1.7 \pm 1.3^{\mathrm{b}}$ & 10 \\
\hline Score 2 & $1.14 \pm 1.22$ & $1.28 \pm 1.42$ & $1.28 \pm 1.42^{b}$ & 7 \\
\hline Score 3 & - & - & - & 0 \\
\hline \multicolumn{5}{|c|}{ Saliva buffering capacity } \\
\hline Score 0 & $0.43 \pm 0.85$ & $0.52 \pm 0.93$ & $0.49 \pm 0.89^{a}$ & 95 \\
\hline Score 1 & $0.6 \pm 0.55$ & $0.6 \pm 0.55$ & $0.6 \pm 0.55^{\mathrm{a}}$ & 5 \\
\hline Score 2 & - & - & - & 0 \\
\hline \multicolumn{5}{|c|}{ Caries experience } \\
\hline Score 0 & $0.33 \pm 0.81$ & $0.33 \pm 0.81$ & $0.33 \pm 0.81^{a}$ & 6 \\
\hline Score 1 & $0.44 \pm 0.90$ & $0.54 \pm 0.85$ & $0.51 \pm 0.73^{a}$ & 21 \\
\hline Score 2 & 0 & 0 & $0^{\mathrm{a}}$ & 27 \\
\hline Score 3 & $0.57 \pm 0.75$ & $0.68 \pm 0.79$ & $0.64 \pm 0.80^{a}$ & 46 \\
\hline
\end{tabular}

*Different letters in the same column indicate significant differences between the different categories of each variable. 
beneficial to show the relative strengths of several risk models. Predictor variables are sometimes added to risk models to construct a model that will predict with high accuracy; therefore, the effect of risk predictors on the risk factors should be carefully evaluated. A prediction model is used when the appropriate interventions are known and the main object is to identify high-risk and low-risk individuals. Prediction models may predict the risk more accurately than a risk model, but the predictor variables will not influence the incidence of caries as most of them are immutable to change. The prediction models are generally cost-effective and require minimum effort to determine so they are the models of choice. However, the presence of powerful predictors in these models may mask the effects of related risk factors. ${ }^{9,21}$

In the current literature, studies on caries risk assessment have generally used the risk models that include both risk and predictor variables. ${ }^{21-24}$ Scheinen et $\mathrm{al}^{22}$ reported that plaque amount, lactobacillus and candida count of saliva and caries history of root caries were the most powerful explanatory factors according to their caries risk model for 62 year old patients. Al Ghanim et $\mathrm{al}^{23}$ assessed the efficacy of factors; such as plaque index, age when a child started tooth brushing, use of sweetened milk, age breastfeeding was stopped, nocturnal bottle feeding with milk formula, frequency of use of soft drinks, frequency of consumption of sweets and age at first dental visit in a caries risk model developed for 3-5 year old children. Regression analyses showed plaque index, use of sweetened milk in bottle, frequency of consumption of soft drinks and child's age at the first dental visit to be significant. Disney et a ${ }^{21}$ evaluated saliva microbial tests, socioeconomical and patients' oral hygiene care criterions together in the caries risk model developed by this group for 6-10 year old children. In that model, the most powerful explanatory factors were found to be DMFS, pits and fissure morphology and the clinician's prediction of caries risk. Powell et al ${ }^{24}$ proposed that caries risk was associated with DMFS, high bacterial counts, gender and Asian ethnicity according to the regression risk model for 60 year old patients. In the current study, the evaluation of: caries experience, related general disease, diet content, diet frequency, amount of plaque, mutans streptoccocci counts, fluoride program, saliva secretion rate, and saliva buffering capacity using logistic regression analyses revealed that diet frequency, saliva secretion rate and plaque amount were the significant factors associated with higher caries incidence. The variation of the results from different risk models may be attributed to the dif-

Table 5. The odds ratio for the different Cariogram groups, diet frequency scores, plaque amount scores, and saliva secretion rate scores.

\begin{tabular}{|c|c|c|c|c|}
\hline Category & $B$ value & Odds ratio & $p$ value & $\% 95 \mathrm{Cl}$ for odds ratio \\
\hline $81-100 \%$ (reference value) & - & - & 0.003 & - \\
\hline $61-80 \%$ & 20,222 & 30.02 & 0.000 & $1.45-3.24$ \\
\hline $41-60 \%$ & 22,407 & 50.45 & 0.000 & $1.26-2.722$ \\
\hline $21-40 \%$ & 21,203 & 40.27 & 0.000 & $1.12-1.932$ \\
\hline $0-20 \%$ & 22,407 & 80.3 & 0.000 & $1.243-2.129$ \\
\hline \multicolumn{5}{|l|}{ Plaque amount score 0} \\
\hline (reference value) & & - & - & - \\
\hline Plaque amount score 1 & 1,504 & 4.5 & 0.006 & $1.510-2.703$ \\
\hline Plaque amount score 2 & 2,736 & 15.42 & 0.011 & $1.871-3.232$ \\
\hline Plaque amount score 3 & 3,807 & 45.00 & 0.004 & $1.353-2.993$ \\
\hline \multicolumn{5}{|l|}{ Diet frequency score 0} \\
\hline (reference value) & & - & - & - \\
\hline Diet frequency score 1 & 2,213 & 13,594 & 0.14 & $1.689-3.431$ \\
\hline Diet frequency score 2 & 2,610 & 43.5 & 0.002 & $1.103-3.188$ \\
\hline Diet frequency score 3 & 4,178 & 65.25 & 0.000 & $1.442-2.921$ \\
\hline \multicolumn{5}{|l|}{ Saliva secretion rate score 0} \\
\hline (reference value) & & - & - & - \\
\hline Saliva secretion rate score 1 & 3,629 & 37,687 & 0.031 & $1.449-6.284$ \\
\hline Saliva secretion rate score 2 & 3,224 & 25,125 & 0.042 & $1.823-10.628$ \\
\hline
\end{tabular}


ferences in the parameters and age groups. Investigators claimed that different risk models should be used for different ages because different risk factors are effective in children, adults and older people. Zero et al ${ }^{25}$ pointed out that different risk factors have to be taken into consideration when assessing caries risk for different ages in their review related to caries risk models developed for different ages. In the same review, the following variables were found to be significant for the age groups indicated: primary teeth in children-family education, previous caries experience and socioeconomic conditions; permanent teeth in children and adolescents - DMFS, predicted caries by clinician and pit and fissure morphology; and for permanent teeth in adults - education and marital status.

The most recent innovation in caries risk assessment has been the development of a computer program called Cariogram by which the caries risk profile can be formed and graphically represented to the patients. This program is both a prediction model and risk model because it predicts who is at risk and it identifies the risk factors to determine the appropriate intervention plan. ${ }^{14}$ Hansel Petersson et al ${ }^{13}$ compared the efficacy of caries experience, related general disease, diet content, diet frequency, amount of plaque, mutans streptoccocci counts, fluoride program, saliva secretion rate, saliva buffering capacity and Cariogram in 10-11 year old children. They found the Cariogram to be the most powerful explanatory factor in their study. Hansel Petersson et $\mathrm{al}^{15}$ claimed that Cariogram was able to assigned the elderly individuals (between 55-75 years old) into risk groups that was compatible with the actual caries outcome. On the other hand, Holgerson et $\mathrm{al}^{26}$ evaluated the efficacy of an age-modified Cariogram for 2 year old children. The authors used only 7 variables of Cariogram; caries experience, mutans streptococci counts, related disease, diet frequency, oral hygiene, fluoride program and clinical judgment. Contrary to the above-mentioned studies, these authors reported that this modified Cariogram was not particularly useful in identifying high caries risk patients in a low-caries community of preschool children. The use of "clinical judgement" may be the reason for this dissimilar result, because the caries risk prediction did not only depend on the Cariogram program in that study. Similarly,
Ruiz Miravet et $\mathrm{al}^{16}$ claimed that it is possible to develop simpler regression models to determine caries risk, based on the predictive variables that correlate most highly with the caries risk obtained with the Cariogram. In the current study, Cariogram was found more effective than the other single variables in young adults. However, similar to the study of Ruiz Miravet et $\mathrm{al}^{16}$ regression model with fewer variables (diet frequency, saliva secretion rate and plaque amount) determined caries risk similar to Cariogram in this particular study. In addition, the regression risk model including 10 variables of Cariogram explained the caries risk at a higher rate than Cariogram. This may be due to the different weighting process of Cariogram from regression analyses which evaluate the same variables equally. Although there is no detailed information about the weighting process of Cariogram, its principles are based on previous studies and case reports. In addition, the developers of this program tried to build the Cariogram algorithm on "full facts and circumstances". ${ }^{14}$ In the present study, diet frequency, saliva secretion rate and plaque amount came into prominence when related to the caries risk for 20-21 year old subjects. The possibility of giving more weight to the factors other than diet frequency, saliva secretion rate and plaque amount in Cariogram might have reduced the efficacy of this program.

Although a regression risk model explained caries risk at a higher rate than Cariogram, it did not thoroughly explain caries formation. As many factors affect caries formation, assessing caries risk is very difficult. Beck et al $^{27}$ suggested that a caries risk model has to include social, microbiological, clinical and environmental variables to successfully predict the caries risk. None of the caries risk models examined in the present study included education or socioeconomical conditions; incorporating these social factors into Cariogram or a regression risk model may increase their efficacy. In addition, age is an important criterion in the caries risk assessment. However, neither Cariogram nor regression risk models considers age while developing a caries risk profile. However, some risk factors are more effective for certain ages. For instance, diet frequency, saliva secretion rate or plaque amount may not be an important risk factor for a different age group.

Three variables of Cariogram were not used in this trial, such as country/area, and groups were 
scored as a standard set and clinical judgment was scored as 1, similar to the previous studies on the efficacy of Cariogram. ${ }^{13-15}$ Using these options may increase the efficacy of this program.

\section{CONCLUSION}

The Cariogram program is effective and has some advantages such as making recommendations for preventive care and increasing patient motivation with its pie chart presentation so it can be used in the caries risk assessment instead of single variables. However, it might be possible to develop simpler models with regression analyses to determine caries risk. Assessing caries risk using fewer variables by regression analyses may restrict the use of Cariogram as this method is less time consuming and more economic. However, these models must be evaluated in the longitudinal clinical studies.

\section{CONFLICT OF INTEREST}

The authors declare that they have no conflict of interest.

\section{REFERENCES}

1. Harel-Raviv M, Laskaris M, Chu KS. Dental caries and sugar consumption into the 21st century. Am J Dent 1996;9:184190.

2. Øgaard B. The cariostatic mechanism of fluoride. Compend Contin Educ Dent 1998;20:10-17.

3. Hicks J, Garcia-Godoy F, Flaitz C. Biological factors in dental caries: role of saliva and dental plaque in the dynamic process of demineralization and remineralization (part 1). $J$ Clin Pediatr Dent 2003;28:47-52.

4. Addy M, Dummer PM, Griffiths G, Hicks R, Kingdon A, Shaw WC. Prevalence of plaque, gingivitis and caries in 11-12-year-old children in South Wales. Compend Contin Educ Dent 1986;14:115-118.

5. Tagliaferro EP, Pereira AC, Meneghim Mde C, Ambrosano GM. Assessment of Dental Caries predictors in a sevenyear longitudinal study. J Public Health Dent 2006;66:169173.

6. Zhang Q, Bian Z, Fan M, van Palenstein Helderman WH. Salivary mutans streptococci counts as indicators in caries risk assessment in 6-7-year-old Chinese children. $J$ Dent 2007;35:177-180.

7. Azrak B, Callaway A, Willershausen B, Ebadi S, Gleissner C. Comparison of a new chairside test for caries risk assessment with established methods in children. Schweiz Monatsschr Zahnmed 2008;118:702-708.
8. Wigen TI, Wang NJ. Caries and background factors in Norwegian and immigrant 5-year-old children. Community Dent Oral Epidemiol 2010;38:19-28.

9. Beck JD. Risk revisited. Community Dent Oral Epidemiol 1998;26:220-225.

10. Stamm JW, Stewart PW, Bohannan HM, Dishey JA, Graves RC, Abernathy JR. Risk assessment for oral diseases. $A d v$ Dent Res 1991;5:4-17.

11. Tinanoff N. Critique of evolving methods for caries risk assessment. J Dent Educ 1995;59:980-984.

12. Powell LV. Caries risk assessment: relevance to the practitioner. J Am Dent Assoc 1998;129:349-353.

13. Hansel Petersson G, Twetman S, Bratthall D. Evaluation of a computer program for caries risk assessment in schoolchildren. Caries Res 2002;36:327-340.

14. Bratthall D, Hansel Petersson G. Cariogram-a multifactorial risk assessment model for a multifactorial disease. Community Dent Oral Epidemiol 2005;33:256-264.

15. Hansel Petersson G, Fure S, Bratthall D. Evaluation of a computer-based caries risk assessment program in an elderly group of individuals. Acta Odontol Scand 2003;61:164171.

16. Ruiz Miravet A, Montiel Company JM, Almerich Silla JM. Evaluation of caries risk in a young adult population. Med Oral Patol Oral Cir Bucal 2007;12: E412-418.

17. Mojon P. Oral health and respiratory infection. J Can Dent Assoc 2002;68:340-345.

18. Könönen E, Jousimies-Somer H, Bryk A, Kilp T, Kilian M. Establishment of streptococci in the upper respiratory tract: longitudinal changes in the mouth and nasopharynx up to 2 years of age. J Med Microbiol 2002;51:723-730.

19. http://www.mah.se/upload/OD/cariogram\%20program\%20caries/cariogmanual201net.pdf, laccess date: 22.05.2011).

20. World Health Organization. Oral health surveys: Basic methods. $3^{\text {rd }}$ ed., Geneva; WHO; 1987. p. 39-44.

21. Disney JA, Graves RC, Stamm JW, Bohannan HM, Abernathy JR, Zack DD. The University of North Carolina caries risk assessment study: further developments in caries risk prediction. Community Dent Oral Epidemiol 1992;20:64-75.

22. Scheinin A, Pienihakkinen K, Tiekso J, Holmberg S. Multifactorial modeling for root caries prediction. Community Dent Oral Epidemiol 1992;20:35-37.

23. Al Ghanim NA, Adenubi JO, Wyne AA, Khan NB. Caries prediction model in pre-school children in Riyadh, Saudia Arabia. Int J Paediatr Dent 1998;8:115-122.

24. Powell LV, Leroux BG, Persson RE, Kiyak HA. Factors associated with caries incidence in an elderly population. Community Dent Oral Epidemiol 1998;26:170-176. 
25. Zero D, Fontana M, Lennon AM. Clinical applications and outcomes of using indicators of risk in caries management. J Dent Educ 2001;65:1126-1132.

26. Holgerson PF, Twetman S, Stecksen-Blicks C. Validation of an age-modified caries risk assessment program (Cariogram) in preschool children. Acta Odontol Scand 2009;67:106-112.

27. Beck J, Kohout R, Hunt R. Identification of high risk adults; attitudes, social factors and disease. Int Dent J 1988;38:231 238. 